\title{
Hereditary Sensory and Autonomic Neuropathy Type V: A Rare Case Report
}

\author{
Shilpa Sasalawad ${ }^{1}$ Sarakanuru Krishnappa Srinath' ${ }^{1}$ Sushma Hoddetty Shivarama ${ }^{2}$
}

'Department of Pedodontics and Preventive Dentistry, Government Dental College and Research Institute, Bangalore, India

${ }^{2}$ Department of Dentistry, K.R. Hospital, Mysore Medical College, Mysore, Karnataka, India

\author{
Address for correspondence: Shilpa Sasalawad, Department of \\ Pedodontics and Preventive Dentistry, Government Dental College \\ and Research Institute, Bangalore 560002, India \\ E-mail: shilpa.sasalawad@gmail.com
}

\begin{abstract}
Hereditary sensory and autonomic neuropathy type V (HSAN V) is a rare disorder that mainly affects the sensory neurons, which conduct the transmission of sensations such as pain, temperature, and touch. It is an autosomal recessive disorder characterized by a lack of deep pain perception. Traumatic injury and self-mutilation are persistent features of this disorder. The challenge in dentistry is to manage the self-mutilation behavior, avoiding severe damage, especially oral structures, hands, and fingers. We report a case of an 8-year-old female child with HSAN type V, having the typical clinical manifestations of pain insensitivity causing self-mutilation. We discuss the comprehensive dental treatment of the patient with HSAN V.
\end{abstract}

Keywords: Autosomal recessive, hereditary sensory and autonomic neuropathy, pain, self-mutilation

\section{Introduction}

Pain is an inborn reflex and is highly protective in nature. It guards the tissues of the body against the noxious stimuli and possible tissue destruction. It interferes with patient's quality of life and general functioning. The International Association for the Study of Pain, defines pain as "an unpleasant sensory and emotional experience associated with actual or potential tissue damage, or described in terms of such damage".[1]

HSANs are neurodegenerative disorders of the peripheral nervous system involving a different degree of sensory and autonomic disturbances, characterized by, severe ulcero-mutilations, first described in 1852, by Nelaton.[2] Based on age of onset, mode of inheritance, predominant clinical features, HSANs are classified as type I-V; recently HSAN type VI has been added to the list.[3] HSAN type $\mathrm{V}$ is the rarest of the five caused due to mutation in the NGFB gene, located on chromosome 1(1p13.2-p.2), coding for Nerve Growth Factor B (NGFB), that is important in the development and survival of nerve cells (neurons), including sensory neurons.[4] It is characterized by marked absence of pain and temperature sensations with intact pressure proprioception, pressure and unimpaired touch, normal intellectual abilities associated with decreased or normal sweating.[5]

\section{Case Presentation}

An 8-year-old girl reported to Pedodontics and Preventive Dentistry Department, with a chief complaint of an ulcer on the lower lip and multiple carious teeth. Family history revealed she is the second daugh-

How to cite this article: Sasalawad S, Srinath SK, Hoddetty Shivarama S. Hereditary Sensory and Autonomic Neuropathy Type V: A Rare Case Report. J Pediatr Dent 2020;6(2):53-56 
ter of the second-degree consanguineous marriage, and the first child is normal. There was no positive family history with HSAN. The patient's mother noticed delayed milestones by 3-6 months and didn't respond to painful stimuli like vaccination and injury. At the age of 8 months, she had a total absence of blink reflex and corneal sensation bilaterally, diagnosed as congenital corneal anesthesia. Parents gave a history of biting lips and tongue after the eruption of teeth.

General examination revealed the patient was pallor, eyes showed absence of blink and corneal reflex and bilateral corneal anesthesia. Ophthalmoscopic examination

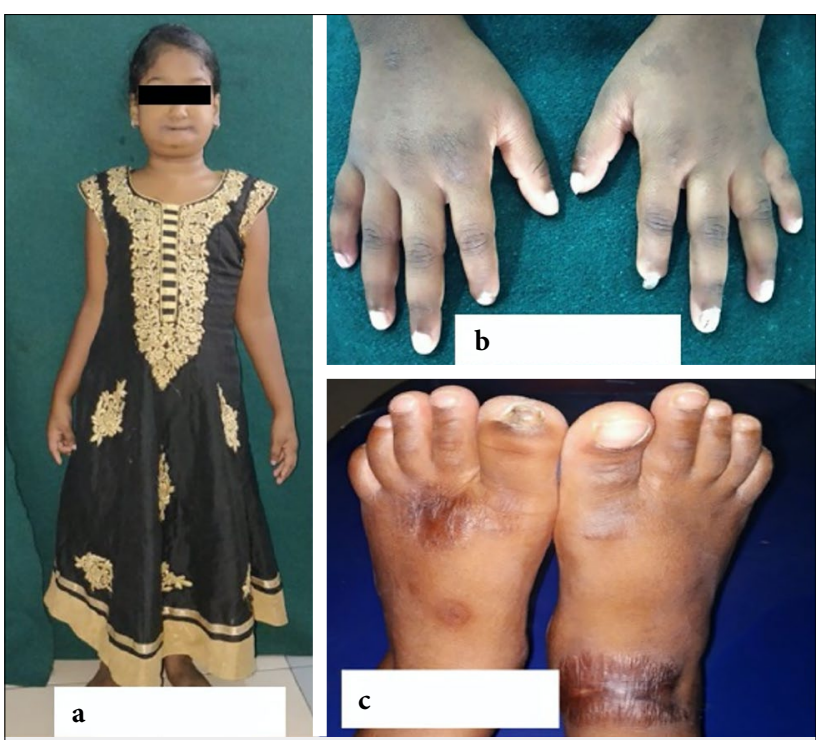

Figure 1. (a) General physical examination, (b) Bilateral distal resorption of the index finger, (c) Scars and burns over the foot showed bilateral corneal opacities with only $10 \%$ of vision (Fig. 1a). Bilateral distal resorption of the index finger and right great toe with spoon-shaped nails was evident (Fig. 1b). Scars and burns over the extensor aspect of knees, thighs, and feet were seen (Fig. 1c). Chromosome analysis was done for karyotype results, which showed female karyotype (Fig. 2a). Electroneuromyography (ENMG) showed normal study.

Extra-oral examination (Fig. 2b) revealed normal upper lip with a mild dryness and angular cheilitis with limited mouth opening. Thin and fibrosed lower lip with traumatic ulcer due to constant biting. Complete loss of lower teeth caused loss of support to lower lip resulted in lip trap. Intraoral examination (Figs. 3a and $3 \mathrm{~b})$ revealed complete resection of the tongue and injuries over the tongue due to constant biting. Hard tissue examination revealed presence of $16,55,14,52,11,21$, 22, 24 and 26. Dental caries with respect to 55, 11, 21, and root stump in relation to 52 . The mandibular ridge was totally resorbed and completely edentulous. Parents gave a history of autoextraction of the deciduous teeth. Atrophy of the lower alveolar bone and raw bony surface seen in the lower edentulous ridge. After the complete examination patient was advised for orthopantomogram radiograph (OPG), revealed resorbed lower alveolar bone, embedded bilateral lower first molars (Fig. 3c). Based on clinical findings, a histological feature, sensory and autonomic dysfunction, and karyotype, the case was diagnosed with HSAN Type V. The parents were explained about the possible treatment options and importance of soft tissues (tongue).
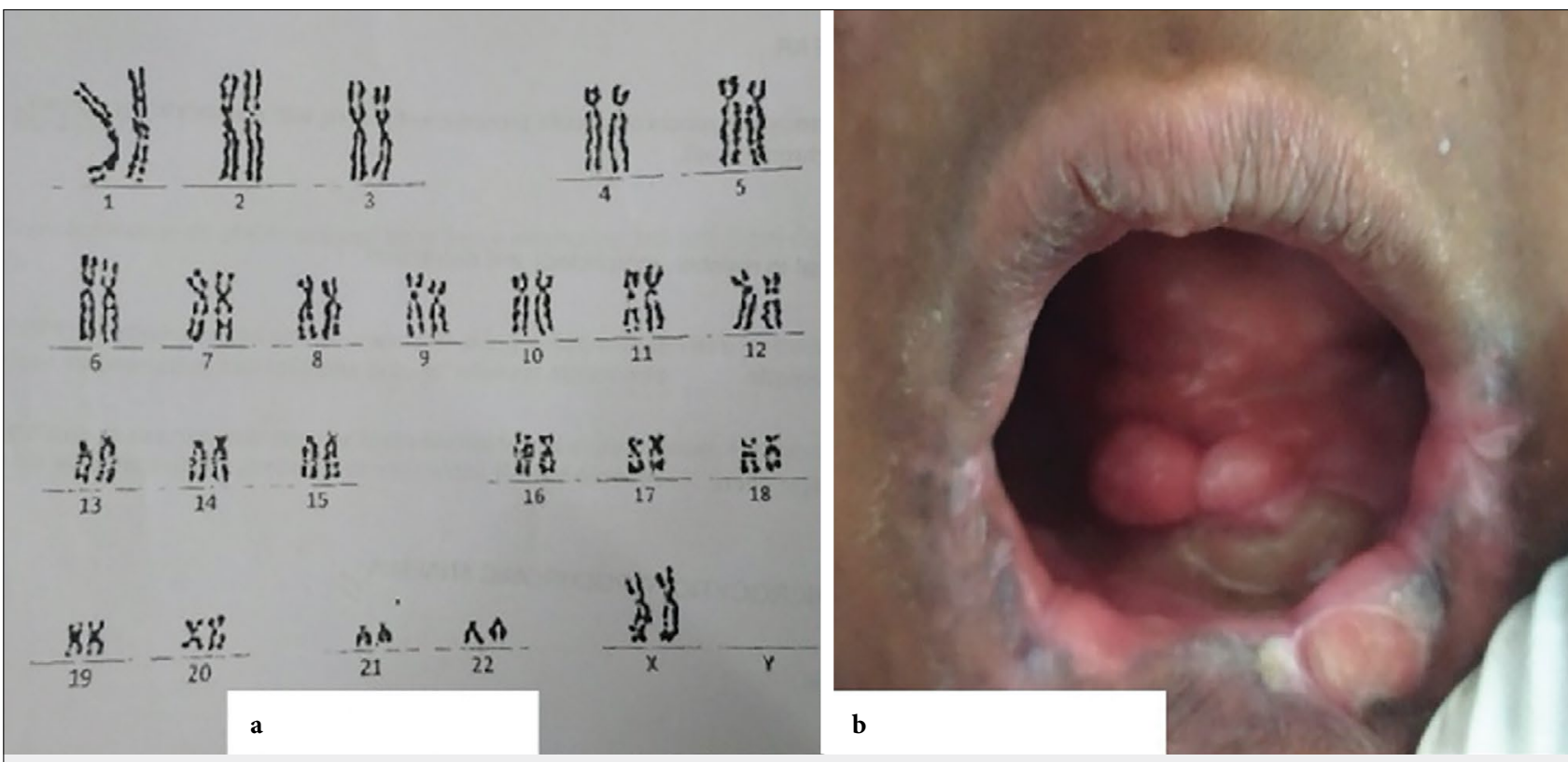

Figure 2. (a) Female karyotype, (b) Extra-oral examination shows ulceration of the lower lip 


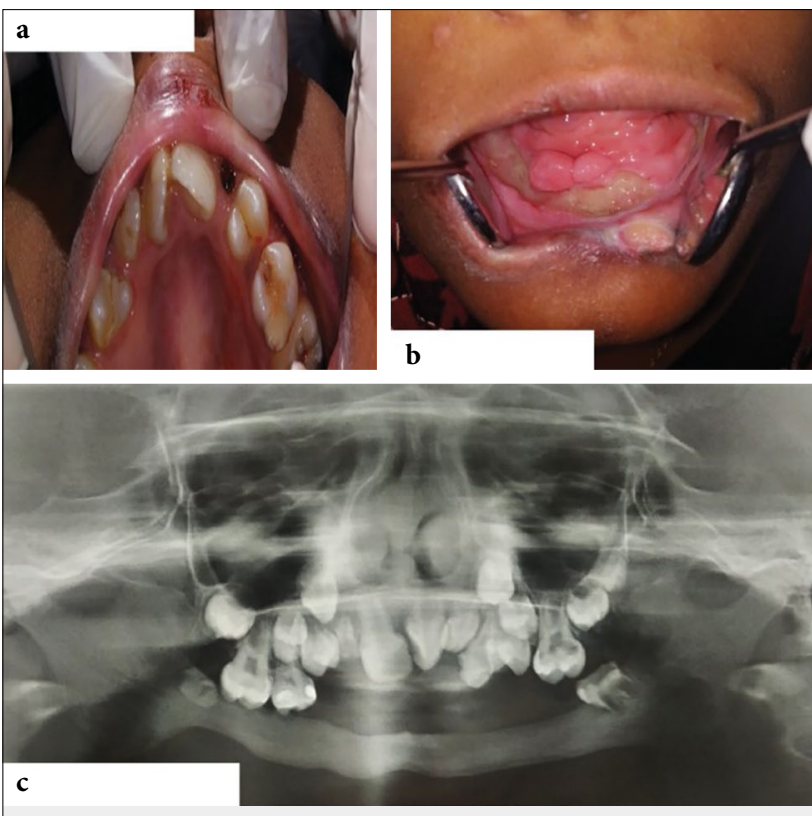

Figure 3. (a) Intraoral examination of the maxillary arch, (b) Intraoral examination of mandibular arch, (c) Orthopantomogram (OPG) revealed resorbed lower alveolar bone, embedded bilateral lower first molars

Alginate impression of the lower lip was made, and the cast was poured with dental stone, splint for the lower lip was fabricated with biocryl sheet using biostar forming machine, advised to wear the splint till healing of the traumatic ulcer on the lip (Figs. $4 \mathrm{a}$ and $4 \mathrm{~b}$ ). After complete cure of the ulcer, bite guard with palatal covering was preferred, and the patient was advised to wear the bite guard and asked to remove it for 1-2 hours interval (Figs. $4 \mathrm{c}$ and $4 \mathrm{~d}$ ).
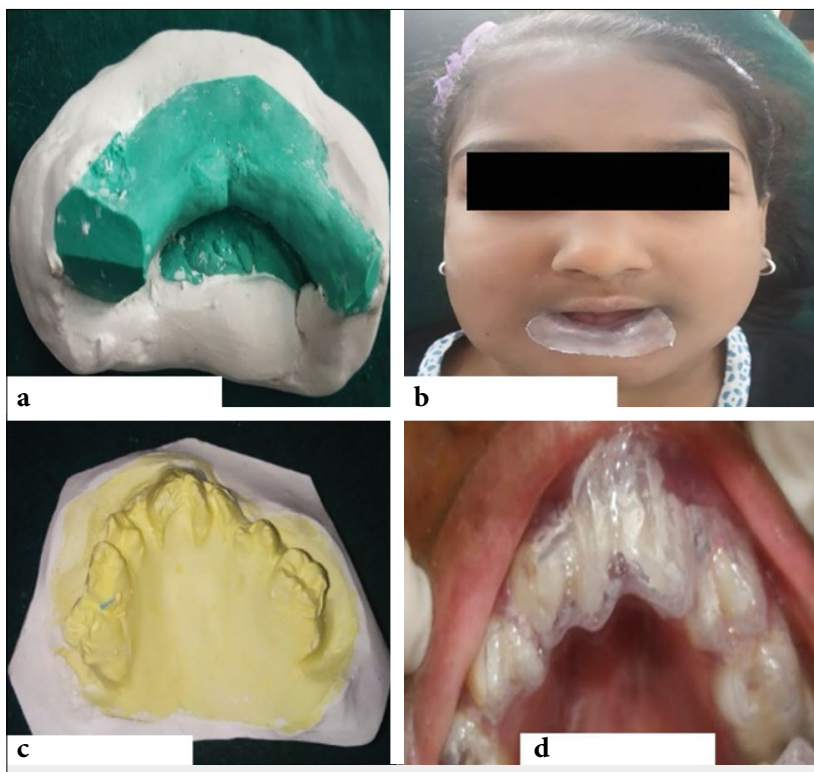

Figure 4. (a) Cast of the lower lip, (b) Lip guard for the lower lip, (c) Cast of the maxillary arch, (d) Occlusal guard after insertion

\section{Discussion}

Hereditary sensory, autonomic neuropathies (HSAN) are a clinically and genetically heterogeneous group of peripheral nervous system disorders. In 1983, Dyck et al recommended the diagnostic criteria for the disease based on histological, microscopic, and morphometric methods for assessing nerve fiber pathology. [6] Although the prevalence of HSAN has not been well established; they appear to be very rare, except in few countries.

Type I: Sensory radicular neuropathy. [4]

Type II: Congenital sensory neuropathy.[3-7]

Type III: Familial dysautonomia.[3-7]

Type IV: Most prevalent type is known as congenital insensitivity to pain with anhidrosis (CIPA).[8]

HSAN V: Congenital indifference to pain. It is an autosomal recessive condition similar to HSAN type IV. It is caused due to mutation in the NGF beta gene (NGFB gene at locus 1p13.2-p.2). NGF- $\beta$ mutation results in a substitution of tryptophan for arginine on position 211 in a highly conserved region of the protein.[4]

Greater degree of anhidrosis and mental retardation is seen in HSAN type IV, compared HSAN type V, in which, patients have normal intelligence and motor development. In HSAN type V, there is severe reduction of unmyelinated nerve fibers and a moderate loss of thin myelinated fibers, where in HSAN type IV normal large myelinated nerve fibers with reduced small myelinated fibers.

Clinical features of HSAN V are insensitivity to pain, reduced thermal sensation, and severe loss of deep pain perception, painless fractures and joint deformities. Self-mutilation is an invariable feature of this disorder most often involving the teeth, lips, tongue, ears, eyes, nose and fingers. Oral management of these patients should focus on preventing injury to the tongue, lips, teeth, and oral mucosa. Children will require grinding of the teeth or extraction of all teeth or bite guard to prevent self-mutilation injury to the tongue and lips.[9]

\section{Dental management}

There is no definitive treatment for the HSAN type V, management is supportive. As self-mutilation is invariably a constant feature, oral management of these patients should focus on preventing injury to the tongue, lips, oral mucosa, and teeth. Selective grinding of sharp edges of teeth and extraction of offending teeth. Use of mouth guards or tongue guards to prevent injury to soft tissues.[10] The use of intra oral appliances may 
be difficult in some patients as the self-mutilation would have begun with the eruption of primary incisors. The removal of such teeth may be unavoidable in some cases. Prevention of dental caries is crucial to intercept the spread of infection. Thus, the dental team should therefore continuously monitor these patients throughout their lifetime.[8]

\section{Conclusion}

Congenital indifference to pain is a very rare disorder. These patients suffer, even without pain. Genetic counseling and prenatal diagnosis should be done to prevent the birth of the affected child. Early diagnosis and education to mitigate the trauma to oral tissues and proper care of skin, eye, and dental tissues. The challenge to the dentist is to diagnose and treat appropriately the local infection to reduce the life-threatening complications in later life.

Financial Disclosure: Nil.

Conflict of Interest: None declared.

\section{References}

1. Merskey H, Bogduk N. Part III: Pain Terms: A Current List with Definitions and Notes on Usage. In: Classification of Chronic Pain. IASP Task Force on Taxonomy. 2nd ed. Seattle; IASP Press; 1994;209-214
2. Nelaton M. Affection singuliere des os du pied. Gaz Hop Civ Milit 1852;4:13-20

3. Capsoni S. From genes to pain: nerve growth factor and hereditary sensory and autonomic neuropathy type V. Eur J Neurosci 2014;39(3):392-400 doi:10.1111/ejn.12461

4. Nagasako EM, Oaklander AL, Dworkin RH. Congenital insensitivity to pain: an update. Pain 2003;101(3):213-219 doi:10.1016/ s0304-3959(02)00482-7

5. Houlden H, King RH, Hashemi-Nejad A, et al. A novel TRK A (NTRK1) mutation associated with hereditary sensory and autonomic neuropathy type V. Ann Neurol 2001;49(4):521-525

6. Dyck PJ, Mellinger JF, Reagan TJ, et al. Not 'indifference to pain' but varieties of hereditary sensory and autonomic neuropathy. Brain 1983;106 (Pt 2):373-390 doi:10.1093/brain/106.2.373

7. Yozu A, Haga N, Funato T, Owaki D, Chiba R, Ota J. Hereditary sensory and autonomic neuropathy types 4 and 5: Review and proposal of a new rehabilitation method. Neurosci Res 2016;104:105-111 doi:10.1016/j.neures.2015.10.011

8. Schalka MM, Corrêa MS, Ciamponi AL. Congenital insensitivity-to-pain with anhidrosis (CIPA): a case report with 4-year follow-up. Oral Surg Oral Med Oral Pathol Oral Radiol Endod 2006;101(6):769-773 doi:10.1016/j.tripleo.2005.07.030

9. Kumar AV, Jaishankar HP, Naik P. Congenital insensitivity to pain: Review with dental implications. Indian J Pain 2014;28:13-17

10. Madhura S, Sowrabha, Manjunath, Savitha MR. Hereditary sensory autonomic neuropathy type V: A rare case report. Int J Contemp Pediatr 2018;5:670-672 